\title{
Study on Failure Characteristics and Rock Burst Mechanism of Roadway Roof under Cyclic Dynamic Load
}

\author{
Chunmei Zheng ${ }^{D}$, Jiayan Zheng, Xiaojuan Peng, and Lei Zhou \\ School of Civil Engineering, Chongqing Jiaotong University, Chongqing 400074, China \\ Correspondence should be addressed to Chunmei Zheng; cmzheng2021@163.com
}

Received 6 November 2021; Accepted 29 November 2021; Published 14 December 2021

Academic Editor: Xuepeng Zhang

Copyright (c) 2021 Chunmei Zheng et al. This is an open access article distributed under the Creative Commons Attribution License, which permits unrestricted use, distribution, and reproduction in any medium, provided the original work is properly cited.

Rock burst is a catastrophic phenomenon that often occurs in underground rock mass engineering. In order to reveal the essence of rock burst of a hard roof in the process of roadway excavation, the particle discrete element method is used to establish a roadway model and simulate the disturbance of harmonic dynamic load based on the analysis of a rock burst accident in a deep mine. The crack field, stress field, displacement field, and kinetic energy of roadway surrounding rock disturbed by cyclic dynamic load were analyzed, and the disaster mechanism of roadway impacting roof instability was discussed. The results show that, compared with the roadway support structure under static load that can give full play to its control function of surrounding rock, the roadway surrounding rock will collapse and lose stability in a large area under the roof cyclic dynamic load, and the ordinary supporting structure cannot give full play to its control function of surrounding rock, resulting in the surrounding rock destruction and supporting structure failure. In addition, the essence of rock burst in a hard thick roof is due to the instantaneous superposition of static stress and dynamic load, leading to the instantaneous instability and collapse of roadway roof in a large area. The research is of great significance to further understand the deformation and failure mechanism of roadway surrounding rock under strong impact load, to guide the safe production and prevent the occurrence of rock burst hazard in underground rock mass engineering.

\section{Introduction}

Under the deep rock mass engineering, due to the complex geological occurrence and mining technical conditions, the occurrence frequency of impact dynamic disaster is increasing, and its destruction level is also becoming more and more prominent [1-7]. Figure 1 shows the impact failure characteristics of roadway and a rock burst accident occurring in central and eastern China, and thus it can be seen that roadway rock burst seriously restricts the safe production of a deep mine because of its sudden and violent dynamic appearance. Therefore, studies of rock burst mechanism and control technology are the key problems to ensure the safe production of a deep mine.

Typical roadway rock burst occurs mostly due to dynamic disturbances such as blasting vibration and roof fracture during the advance of mining face [8-11]. In the study of rock burst in underground rock mass engineering, many studies have been carried out to understand the deformation characteristics and failure mechanism of roadway surrounding rock, and a series of effective control methods are put forward [12-21]. However, due to the complexity of site engineering geological conditions and the difference of rock burst types and severity, these current understandings are inadequate. In essence, rock burst is a process of energy stable state gathering and unstable state releasing under the influence of various factors such as external load and internal structure of coal rock, which further increases the complexity of rock burst initiation and occurrence, and rock burst accidents have not been fundamentally controlled [22-26]. In particular, with the continuous increase of the mining depth, the frequency and intensity of its occurrence also tend to increase. Therefore, it is of great significance to study and discuss the characteristics of roadway rock burst 


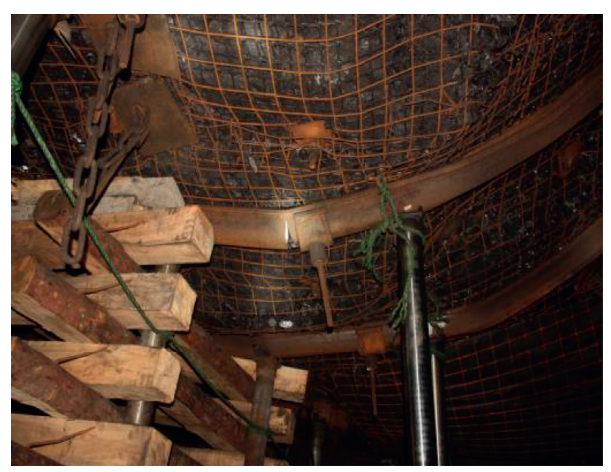

(a)

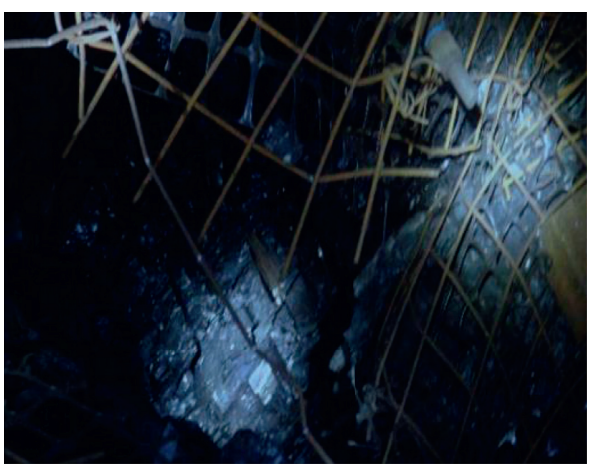

(b)

FIGURE 1: Rock burst hazards. (a) Supporting structure bending. (b) Surrounding rock failure.

under cyclic dynamic load for understanding the occurrence mechanism of rock burst, guiding the safety production of a coal mine, and preventing and controlling the occurrence of rock burst accidents.

In this paper, the rock burst accidents in central and eastern China are analyzed firstly, and in order to further explore the failure characteristics of roadway and rock burst mechanism, the particle discrete element method is used to establish a roadway model and simulate the disturbance of harmonic dynamic load according to a rock burst accident in central and eastern China. The failure zone, stress field, displacement field, and kinetic energy of roadway surrounding rock disturbed by cyclic dynamic load were analyzed. On the basis of this, the mechanism and criterion of rock burst are further discussed.

\section{Methodology}

2.1. Rock Burst Accident. The deep mine located in China is taken as the research background, and a rock burst accident occurred in the course of face cross-heading excavation in the first coal seam. The cross-heading roadway is excavated along the bottom of the coal seam with a buried depth of about $1000 \mathrm{~m}$ and an average thickness of about $7 \mathrm{~m}$. The roof and floor strata are hard thick fine sandstone and medium sandstone. According to the evaluation results of mine bursting liability, the coal seam and floor strata have weak bursting liability, and roof strata have strong bursting liability.

In the course of roadway excavation, a rock burst accident occurred, causing serious damage to the connecting roadway within a range of about $100 \mathrm{~m}$. According to the field investigation, it can be seen from Figure 2 that the roadway damage is mainly characterized by the convergence of two sides and subsidence and falling of the roof. The roadway roof has obvious subsidence and caving, the maximum roof caving reaches $2 \mathrm{~m}$, and the two sides converge, and the floor heave is not obvious, and no large cracks are found. Therefore, it is preliminarily inferred that the partial or integral fracture of the roof sandstone is likely to occur, which induces the impact load, thus leading to the occurrence of coal seam roadway rock burst.
2.2. Establishment of the Particle Flow Model. The parallel bonding model in two-dimensional particle flow code $\left(\mathrm{PFC}^{2 \mathrm{D}}\right)$ is used for modeling and analysis of roadway surrounding rock. According to the parallel bonding contact relationship between particles, the standard sample models of coal, roof, and floor strata with a height of $10 \mathrm{~m}$ and width of $5 \mathrm{~m}$ are established, respectively, as shown in Figure 3(a). Through repeatedly adjusting the mesoscopic mechanical parameters of the standard sample model, the macroscopic mechanical responses of coal, roof, and floor strata are shown in Figure 3(b), and the modeling parameters of each rock stratum are given in Table 1 .

In order to improve the calculation efficiency, the size and content of the model were simplified, and the checked parameters were used to establish a two-dimensional model of $30 \mathrm{~m}$ (width) $\times 30 \mathrm{~m}$ (height). A fixed displacement constraint boundary condition was applied at the lower part of the model, a constant horizontal stress constraint condition was applied at both sides of the model, and a uniformly distributed vertical stress and dynamic load were applied at the top of the model, as shown in Figure 4(a). Assuming that the buried depth of roadway is $1000 \mathrm{~m}$, the bulk density of overlying strata is $25 \mathrm{kN} / \mathrm{m}^{3}$ and the lateral pressure coefficient is 1.2 . The initial stress field with a horizontal stress of $30 \mathrm{MPa}$ and vertical stress of $25 \mathrm{MPa}$ can be satisfied after the model reaches a stress equilibrium state.

The support form of the anchor bolt and anchor cable is shown in Figure 4(b). The roof is supported by the bolt of diameter $22 \mathrm{~mm}$ and length $2500 \mathrm{~mm}$ and the cable of diameter $21.6 \mathrm{~mm}$ and length $7300 \mathrm{~mm}$, and the spacing and row distances are $800 \times 2000 \mathrm{~mm}$ and $2000 \times 2000 \mathrm{~mm}$, respectively. The two sidewalls are supported by the bolt of diameter $20 \mathrm{~mm}$ and length $2500 \mathrm{~mm}$ and the cable of diameter $21.6 \mathrm{~mm}$ and length $4300 \mathrm{~mm}$, and the spacing and row distances are $750 \times 2000 \mathrm{~mm}$ and $2000 \times 2000 \mathrm{~mm}$, respectively.

2.3. Application of Cyclic Dynamic Load. Studies show that an impact source wave can be simplified into a simple harmonic wave, as shown in formula (1), the continuous disturbance time of dynamic load when rock burst occurs is 


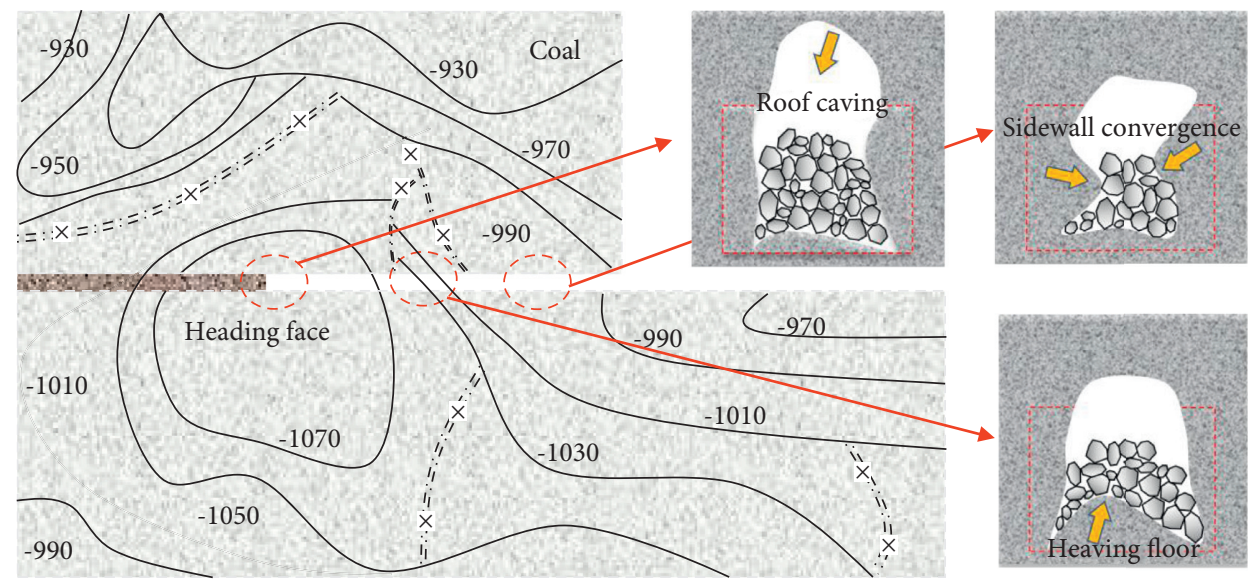

FIGURE 2: Accident location and schematic diagram of roadway instability.

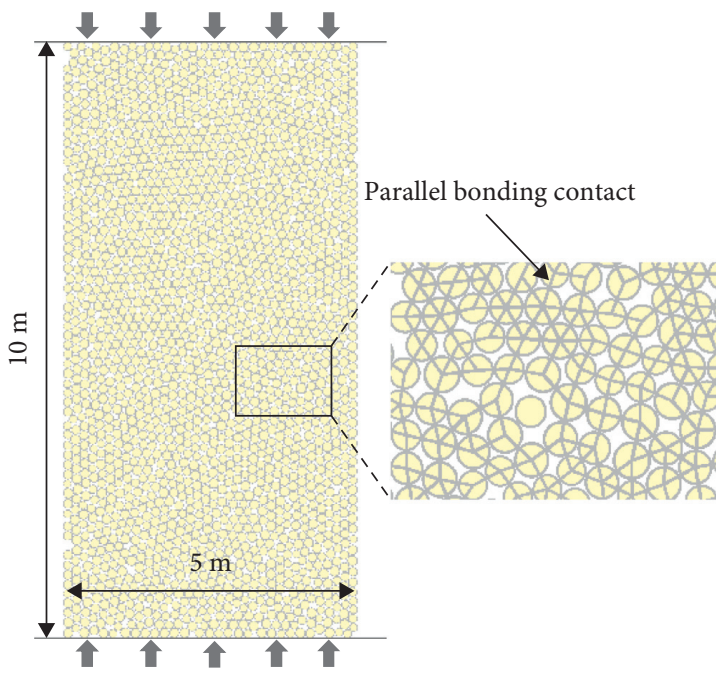

(a)

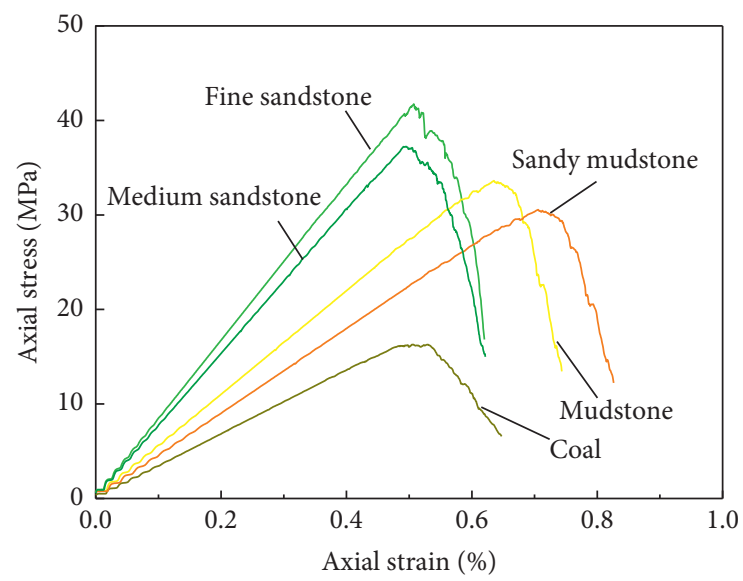

(b)

FIgURE 3: Checking of modeling parameters. (a) Uniaxial compression model. (b) Stress-strain curves.

TABle 1: Mesoscopic parameters of the model in $\mathrm{PFC}^{2 \mathrm{D}}$.

\begin{tabular}{lcccccccc}
\hline Parameter & $\begin{array}{c}\text { Diameter } \\
(\mathrm{m})\end{array}$ & $\begin{array}{c}\text { Density } \\
\left(\mathrm{kg} / \mathrm{m}^{3}\right)\end{array}$ & Porosity & $\begin{array}{c}\text { Friction } \\
\text { coefficient }\end{array}$ & $\begin{array}{c}\text { Contact modulus } \\
(\mathrm{GPa})\end{array}$ & $\begin{array}{c}\text { Bond modulus } \\
(\mathrm{GPa})\end{array}$ & $\begin{array}{c}\text { Cohesion } \\
(\mathrm{MPa})\end{array}$ & $\begin{array}{c}\text { Tensile strength } \\
(\mathrm{MPa})\end{array}$ \\
\hline $\begin{array}{l}\text { Main roof } \\
\text { Immediate }\end{array}$ & $0.09-0.12$ & 2700 & 0.16 & 0.75 & 6.15 & 4.00 & 30 & 20 \\
roof & $0.07-0.09$ & 2300 & 0.16 & 0.70 & 5.35 & 3.15 & 25 & 17 \\
Coal seam & $0.07-0.09$ & 1800 & 0.16 & 0.65 & 2.15 & 2.05 & 10 & 10 \\
Immediate & $0.07-0.09$ & 2100 & 0.16 & 0.70 & 3.00 & 3.00 & 20 & 15 \\
floor & $0.09-0.12$ & 2700 & 0.16 & 0.75 & 6.15 & 3.55 & 30 & 20 \\
Main floor & & & &
\end{tabular}

generally tens of milliseconds, and the frequency is $10-20 \mathrm{~Hz}$.

$$
P(t)=P_{\max }\left[\frac{1}{2}-\frac{1}{2} \cos (2 \pi \omega t)\right]
$$

where $P_{\max }$ is the stress peak of the simple harmonic wave; $\omega$ is the frequency of simple harmonics; and $t$ is the period time.
In order to simulate the dynamic load disturbance of the roof, the FISH language built in particle flow code was used for dynamic load programming, and the disturbed stress wave with a frequency of $20 \mathrm{~Hz}$, period of $50 \mathrm{~ms}$, and peak stress of $35 \mathrm{MPa}$ is applied on the top of the model, as shown in Figure 5. The specific process of dynamic load disturbance simulation is carried out in three stages. Firstly, the model is established under the predetermined boundary conditions, 


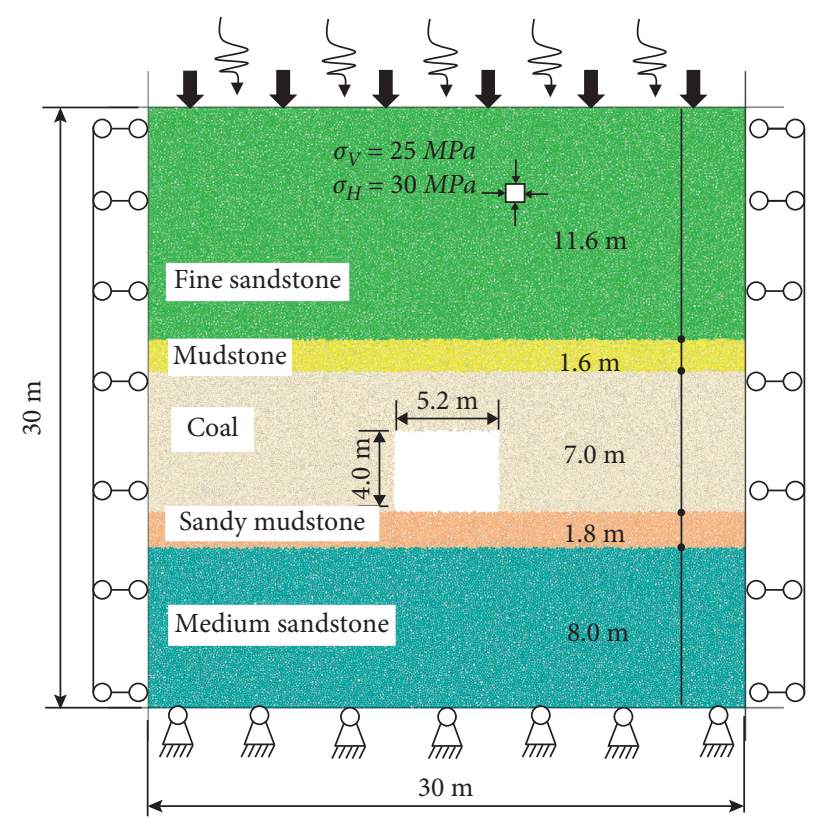

(a)

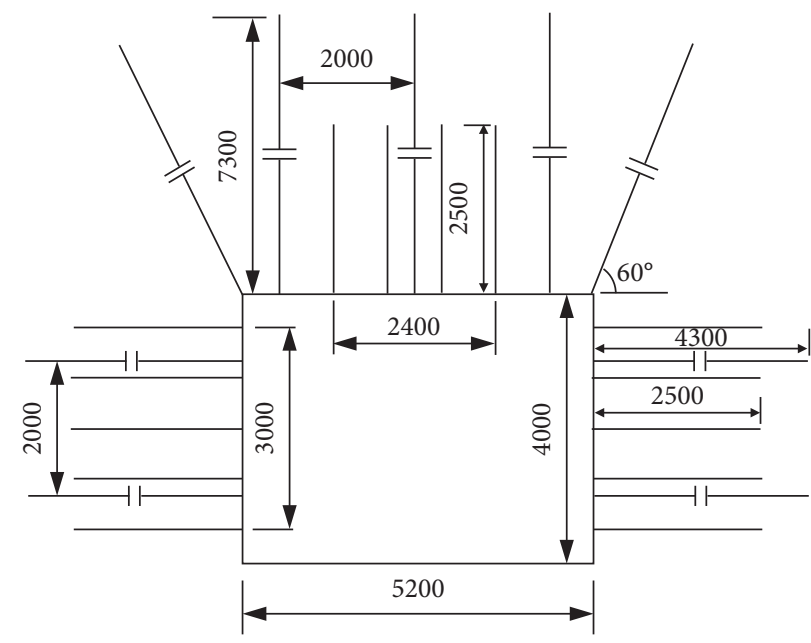

(b)

FIgURe 4: Particle flow model. (a) Boundary conditions. (b) Support parameters (length unit: mm).

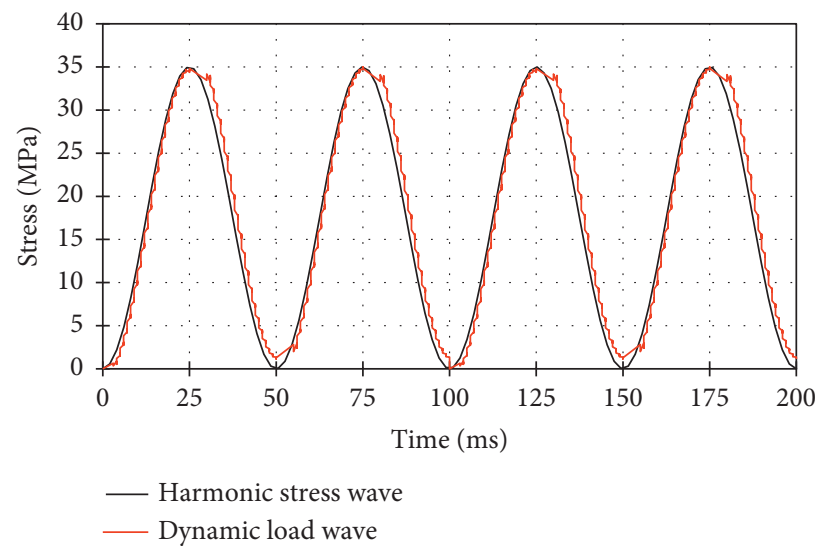

Figure 5: Dynamic load disturbance stress wave.

the model is made to reach the initial equilibrium, and the in-situ rock stress field is simulated. Then, some particles are deleted in the coal seam of the model and calculated to the static load balance to simulate the roadway excavation under high stress. Finally, the disturbed dynamic load is applied on the top of the model, and the process of applying cyclic dynamic load is simulated.

\section{Results and Analysis}

3.1. Crack Field. Figure 6 shows the development law of damaged cracks in the surrounding rock of roadway after cyclic dynamic load. After the first dynamic load, the roof and the two sidewalls were damaged and cracked, respectively. The main cracks in the roof were vertical cracks, and several vertical cracks were connected in a range to form the broken zone. The damaged cracks mainly appeared in the top of the coal, and the broken zone of the roof arch was basically formed. After the second dynamic load, the damage area further expanded, the roof began to collapse, the height and scope of the caving arch further expanded, and the sidewalls appeared obvious damage. After the third dynamic load, the impact energy mainly acted on the sidewalls, and the damage area of the sidewalls began to connect with the damage area of the roof. After the fourth dynamic load, the roof was completely connected with the damage and failure area of both sidewalls, and the failure area developed from arch to cone.

According to the number of microcracks in Figure 7, the total number of cracks shows multiple growths with the increase of impact times, and tensile cracks are the main ones. Therefore, under the impact load of the roof, cracks first appear in roof strata under tensile action due to the small tensile strength of roadway surrounding rock. Under 


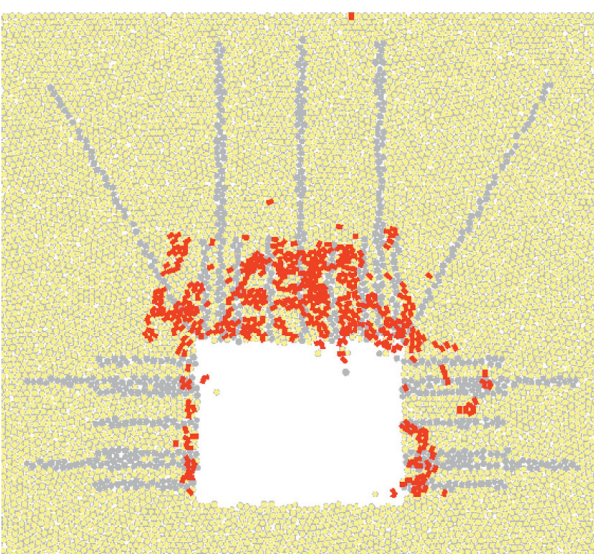

(a)

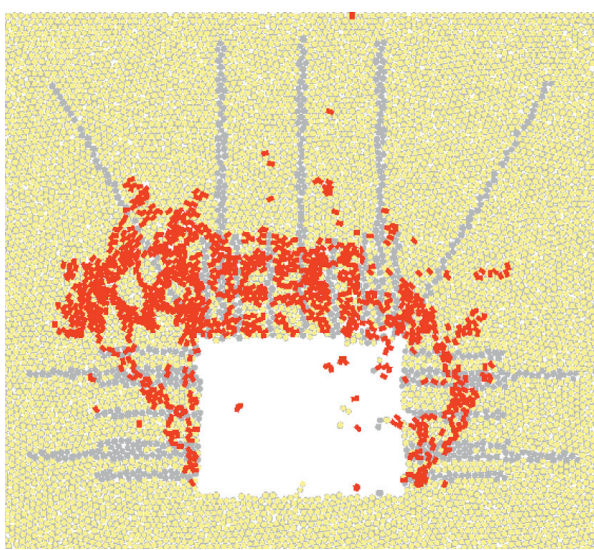

(c)

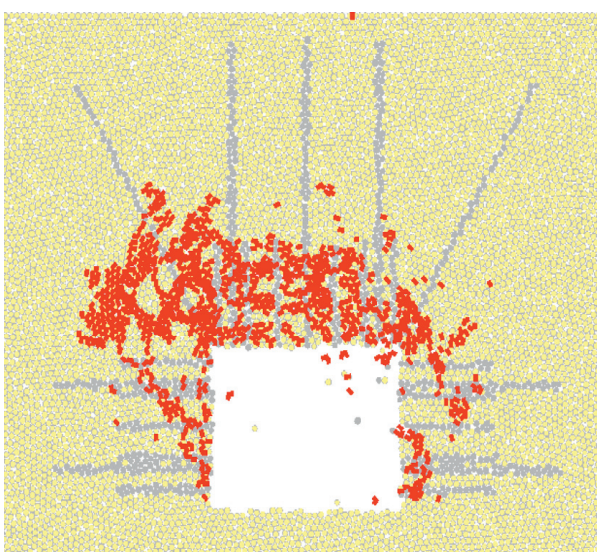

(b)

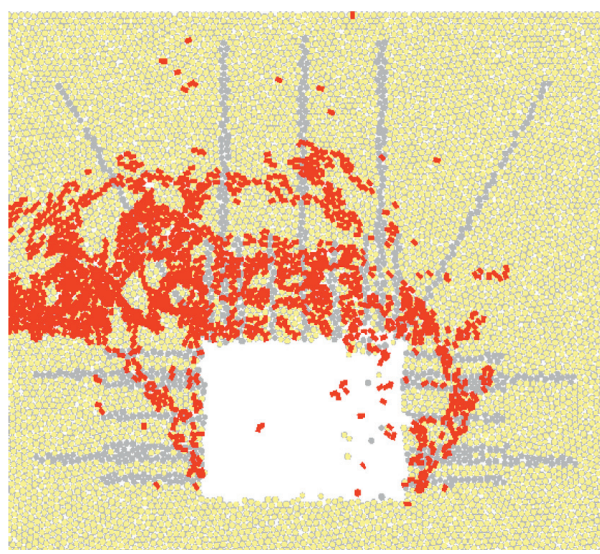

(d)

Figure 6: Crack field. (a) First time. (b) Second time. (c) Third time. (d) Fourth time.

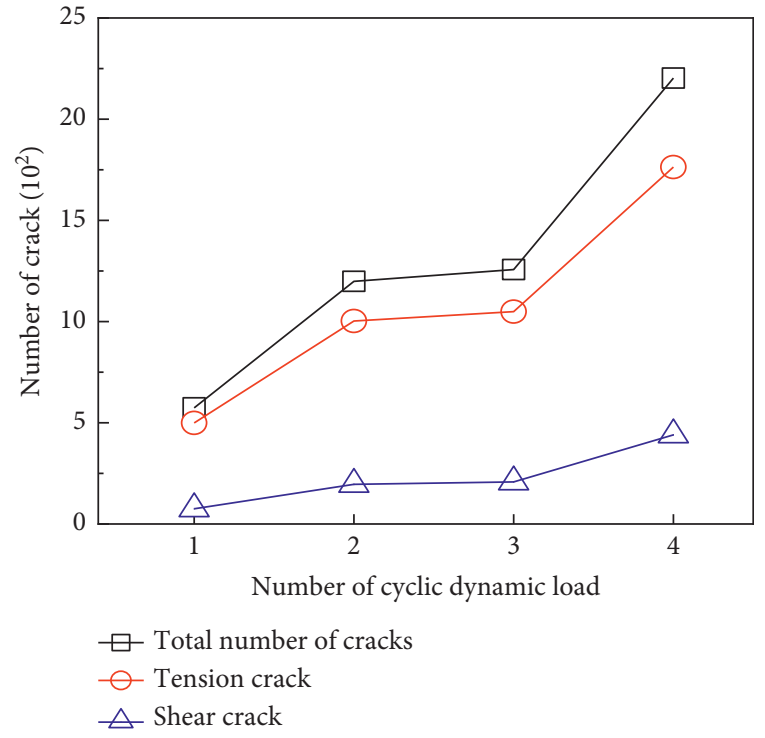

FIgURE 7: Number of microcracks.

the repeated action of dynamic load, the damage cracks continue to develop and expand. Especially after the roof is connected with the cracks on both sides, the shear failure of the surrounding rock occurs as a whole, and the height and scope of the caving zone are further expanded, which makes the roof and both sidewalls of the roadway separate from the support structure, resulting in a large area of roof collapse and splicing phenomenon. Compared with the deformation and failure characteristics of the roadway under static load, large area collapse and instability of roadway roof will occur under dynamic load, and ordinary support forms cannot give full play to the anchoring function, resulting in the destruction of surrounding rock and the failure of the support structure.

3.2. Displacement Field. Figure 8 shows the displacement field of surrounding rock disturbed by the cyclic dynamic load. Under the impact load, the surrounding rock particle units of the roadway move to the interior of the roadway, and the displacement of the roof and two sidewalls is the largest, indicating that the impact load on this area is the most obvious. Especially, the subsidence of the interface area between the roof and the sidewalls is the main part of the deformation of the whole roadway, so the effective control of the subsidence should be considered in the support design. With the increase of impact times, the roof displacement increases significantly, and the range of dynamic load influence increases, while the change of roadway floor displacement is not obvious. 


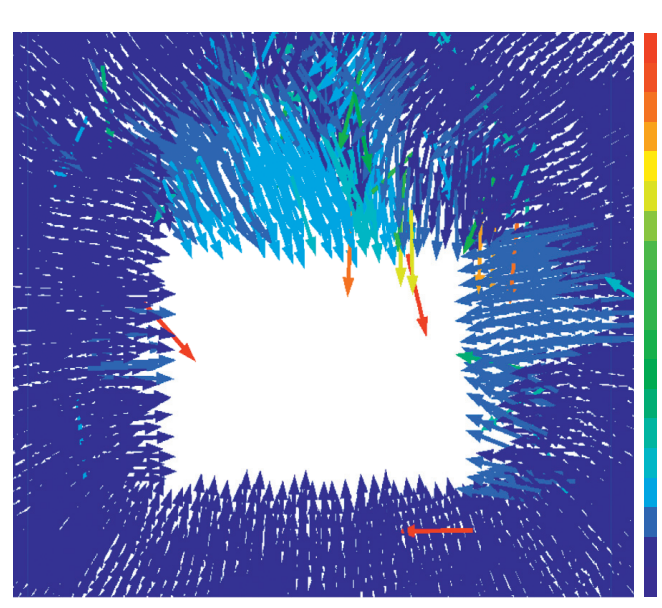

(a)

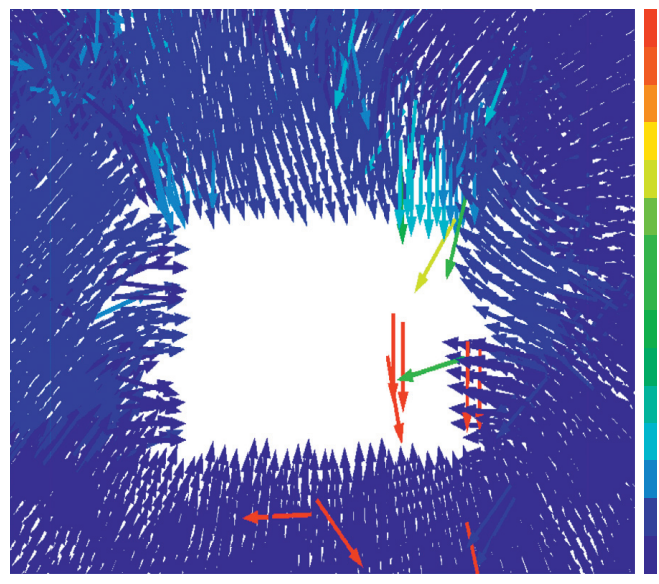

(c)

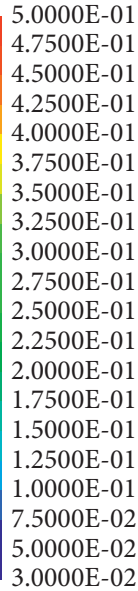

$3.0000 \mathrm{E}-02$

$1.5000 \mathrm{E}+00$ $1.4000 \mathrm{E}+00$ $1.3000 \mathrm{E}+00$ $1.2000 \mathrm{E}+00$ $1.1000 \mathrm{E}+00$ $1.0000 \mathrm{E}+00$ $9.0000 \mathrm{E}-01$ $8.0000 \mathrm{E}-01$ $7.0000 \mathrm{E}-01$ $6.0000 \mathrm{E}-01$ 5.0000E-01 $4.0000 \mathrm{E}-01$ $3.0000 \mathrm{E}-01$ $2.0000 \mathrm{E}-01$ $1.0000 \mathrm{E}-01$ $3.0000 \mathrm{E}-02$

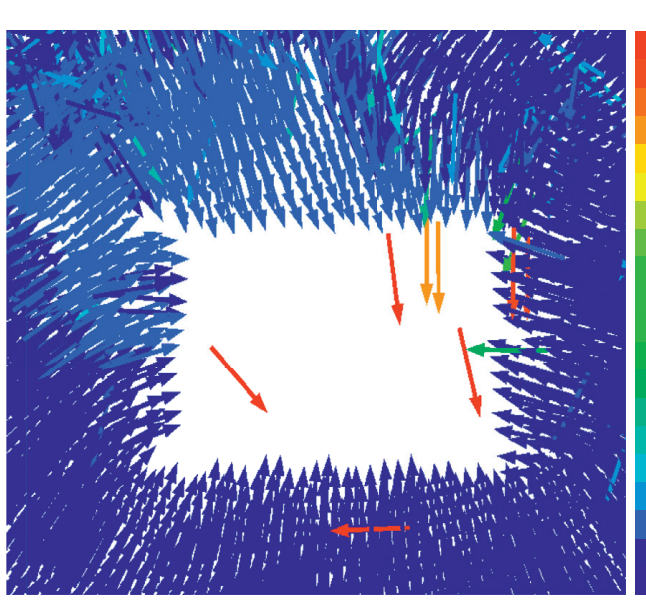

$1.0000 \mathrm{E}+00$ $9.5000 \mathrm{E}-01$ 9.0000E-01 8.5000E-01 $8.0000 \mathrm{E}-01$ 7.5000E-01 7.0000E-01 $6.5000 \mathrm{E}-01$ 6.0000E-01 5.5000E-01 $5.0000 \mathrm{E}-01$ 4.5000E-01 4.0000E-01 $3.5000 \mathrm{E}-01$ $3.0000 \mathrm{E}-01$ $2.5000 \mathrm{E}-01$ $2.0000 \mathrm{E}-01$ $1.5000 \mathrm{E}-01$ $1.0000 \mathrm{E}-01$ $5.0000 \mathrm{E}-02$ $2.0000 \mathrm{E}-02$

(b)

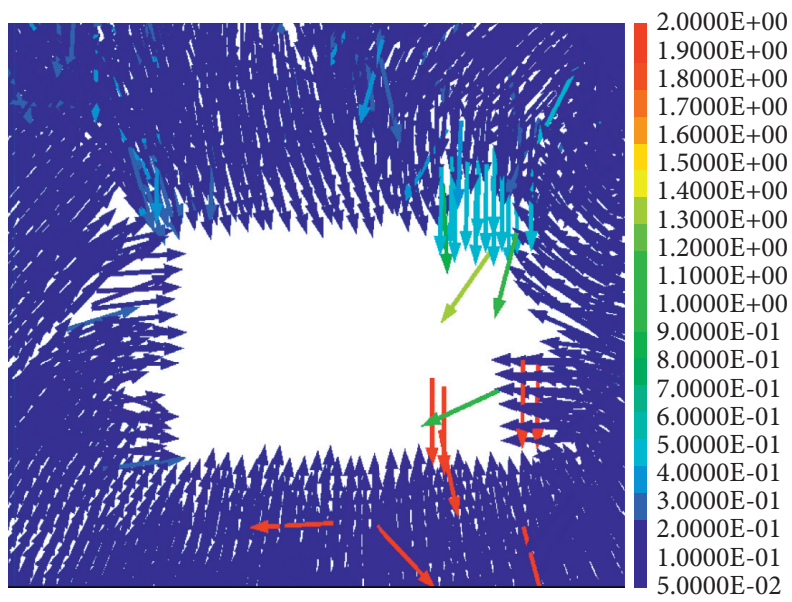

(d)

Figure 8: Displacement field. (a) First time. (b) Second time. (c) Third time. (d) Fourth time.

The built-in energy monitoring module in the program was used to monitor the kinetic energy inside the model during the application of dynamic load, as shown in Figure 9. Under the action of cyclic dynamic load, the kinetic energy of the model is in a relatively high fluctuation process, and the dynamic load makes the roadway surrounding rock in an unstable energy state, revealing the energy driving mechanism of the roadway surrounding rock's large deformation.

3.3. Stress Field. Figure 10 shows the variation rule of contact stress field of the roadway surrounding rock under dynamic load. With the continuous dynamic impact, the contact stress in the damage area of roadway roof tends to be basically stable, especially, the contact stress between particle units in the damage area of coal seam and rock strata is small, indicating that the bearing capacity between particle units in this area is basically lost. Due to the large strength of the main top and main bottom rock strata, they still maintain stability under the condition of large contact stress between the particles caused by the impact load.

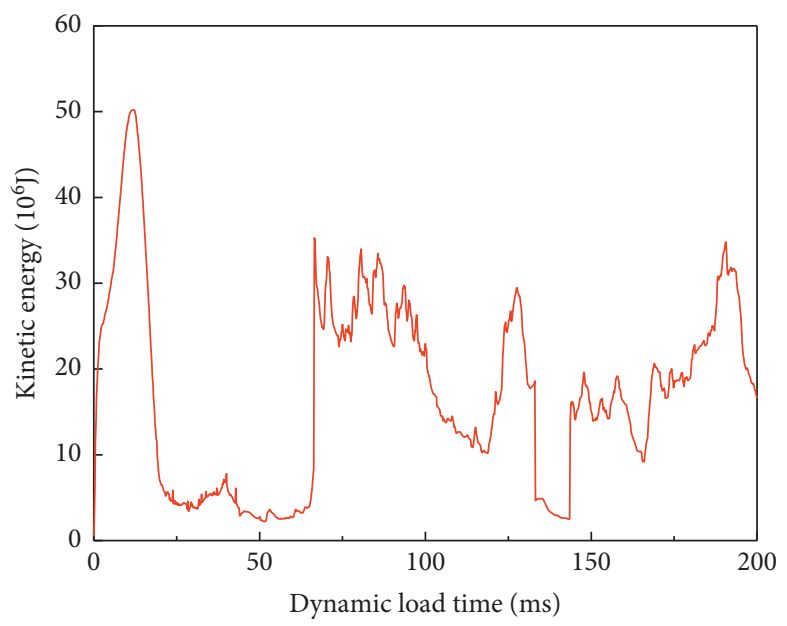

FIGURE 9: Kinetic energy evolution of surrounding rock.

According to the change of roadway roof stress during the dynamic loading time in Figure 11, it can be seen that under the action of dynamic loading, the surrounding rock stress of the roof increases significantly instantly, which has the possibility 


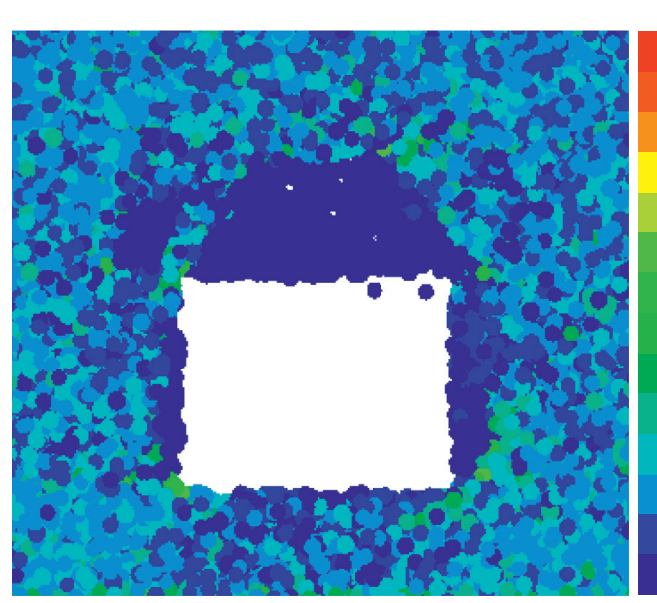

(a)

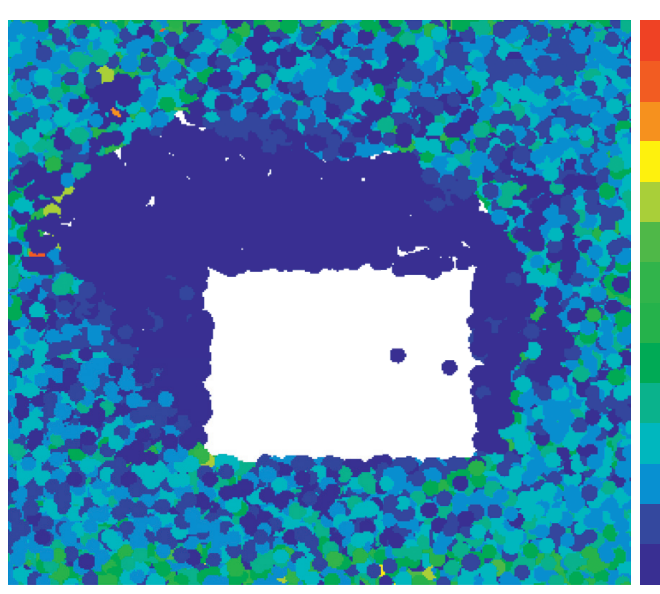

(c)

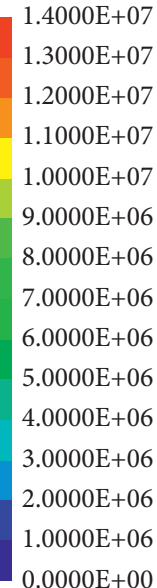

$0.0000 \mathrm{E}+00$

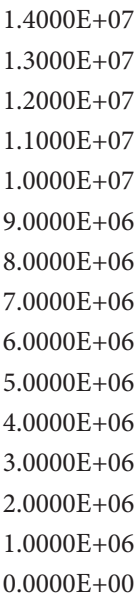

$0.0000 \mathrm{E}+00$
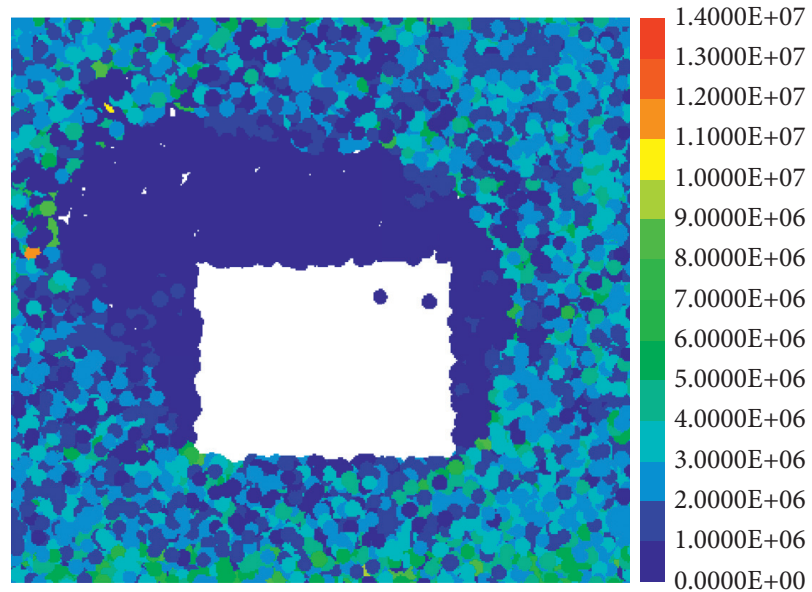

(b)

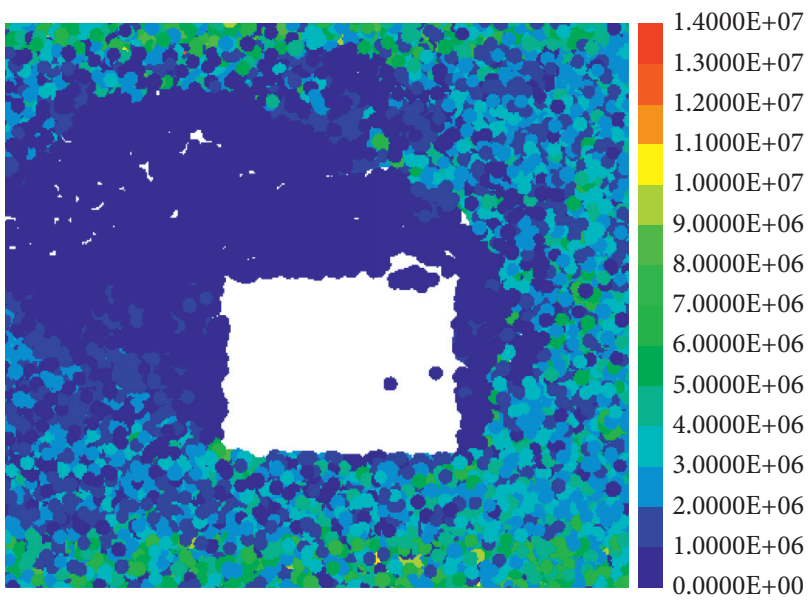

(d)

Figure 10: Stress field. (a) First time. (b) Second time. (c) Third time. (d) Fourth time.

of inducing roof impact instability. The horizontal stress of the roof increases most significantly under dynamic load, and the maximum value of horizontal stress is about 1.5 to 2 times the maximum value of vertical stress. Along with the increase in number of dynamic loads, the maximum stress of roof rock becomes smaller. Therefore, under sustained impact load, the maximum bearing capacity of the surrounding rock of roadway roof falls. The stress variation mechanism of rock impact instability of roadway roof under roof dynamic disturbance is explained indirectly.

\section{Discussion}

4.1. Mechanism of Dynamic Disturbed Rock Burst. According to the above analysis, the essence of rock burst is the sudden instability failure of roadway surrounding rock or support structure under the action of instantaneous high stress. Combined with the failure of roadway, it can be inferred that under the roof impact load, roadway anchor bolts and anchor cables bear large horizontal stress, and the roof is seriously broken and deformed, resulting in anchor bolts and anchor cable cannot effectively restrain the roof and the impact instability of large-area roof caving. Therefore, the rock burst accident can be characterized as the dynamic disaster that the support system does not bear the impact of roof dynamic load in the process of roadway excavation, resulting in large-area instability and roof collapse of roadway roof. It is a typical phenomenon of roadway rock burst that the occurrence is mainly due to large-area roof collapse and instability induced by roof dynamic load disturbance during roadway excavation.

As shown in Figure 12, the roadway is in the in-situ rock stress state before excavation, and after roadway excavation, stress concentration occurs in the surrounding rock due to excavation unloading disturbance.

$$
\sigma_{1}=(1+\lambda) \cdot \sigma_{0},
$$

where $\sigma_{1}$ is the stress of surrounding rock after roadway excavation; $\lambda$ is the stress concentration factor; and $\sigma_{0}$ is the in-situ rock stress before roadway excavation.

Roadway surrounding rock is damaged to an extent under the action of stress concentration. With the increase of surrounding rock damage, the surrounding rock stress decreases, and finally, the stress reaches a stable equilibrium state. 


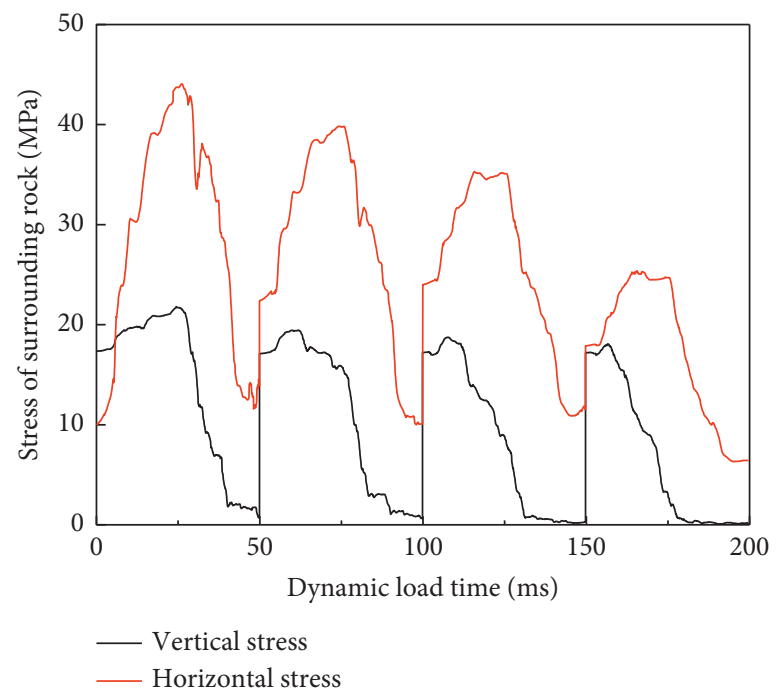

Figure 11: Variation of roof stress under dynamic load disturbance.

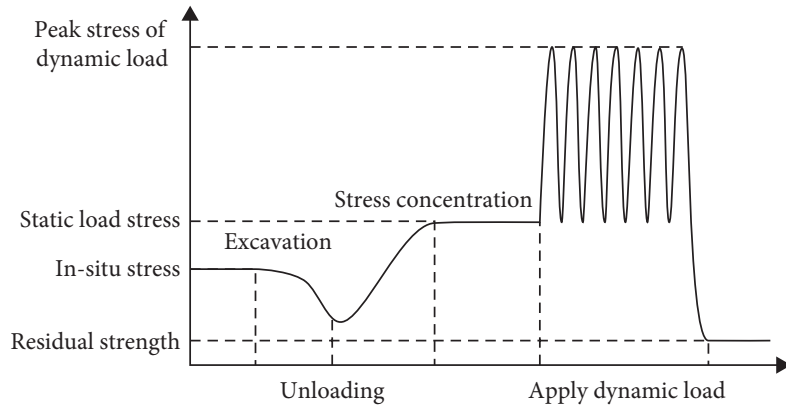

Figure 12: Application process of static load and dynamic load stress.

The extrusion of the roadway support structure and surrounding rock forms a roadway surrounding rockbearing structure, as shown in Figure 13, and this bearing structure can significantly improve the ability of the roadway to resist external load and reduce the deformation and damage of external load to the surrounding rock. Under the roof impact load, the total stress acting on the roadway surrounding rock is the superposition of static stress and dynamic stress, as shown in the following formula:

$$
\sigma_{Z}=\sigma_{J}+n \sigma_{D},
$$

where $n$ is the disturbance coefficient of dynamic load and can be determined according to the impact tendency of coal seam, roof, and floor strata; $\sigma_{Z}$ is the total stress acting on the roadway; $\sigma_{J}$ is the static stress; and $\sigma_{D}$ is the dynamic stress.

Under the impact load, the total stress increases instantaneously, and it determines the damage degree of rock burst. The impact instability of roadway surrounding rock is similar to rock burst in tunnel engineering. The judgment basis of the rock burst critical state in tunnel dynamic disaster research is introduced in the following formula:

$$
\frac{\sigma_{Z}}{p_{i}} \geq I_{c},
$$

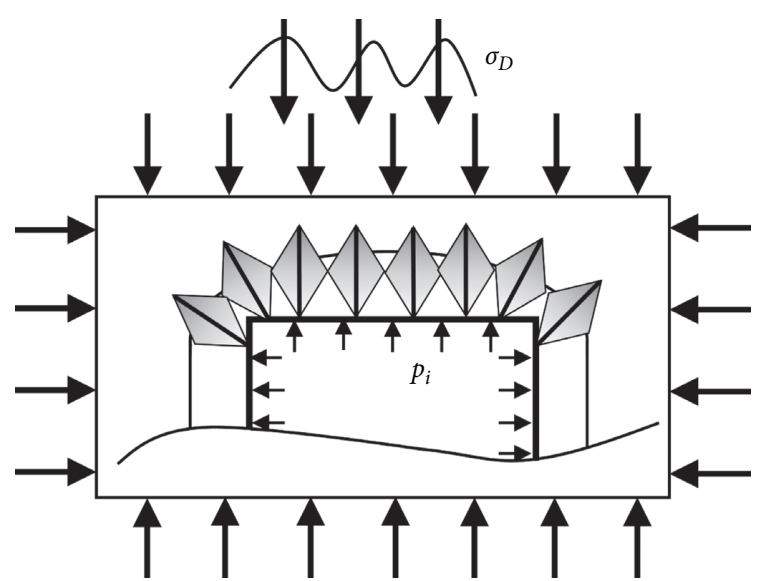

FIGURE 13: Mechanical model of rock burst.

where $p_{i}$ is the support strength of the anchored surrounding rock and $I_{c}$ is the critical index to judge whether the roadway surrounding rock has impact risk. When the ratio of the total stress of roadway surrounding rock to the strength of surrounding rock anchor support is greater than the critical index, the roadway will have impact instability.

4.2. Control Technology of Rock Burst. In summary, the occurrence of the roadway rock burst is the result of the combined action of impact power source, mechanical properties of coal and rock strata, and roadway engineering characteristics. Aiming at the rock burst of the roadway hard roof under dynamic load disturbance, the comprehensive treatment measures of the combination of roof presplitting and sidewall drilling pressure relief holes are further put forward on the basis of improving the technical strength. Presplitting holes shall be arranged on the roof strata, and the end of the presplitting holes shall be arranged in the hard fine sandstone. While at the sidewalls, relief holes with the length of $4.5 \mathrm{~m}$ are arranged, as shown in Figure 14 . 


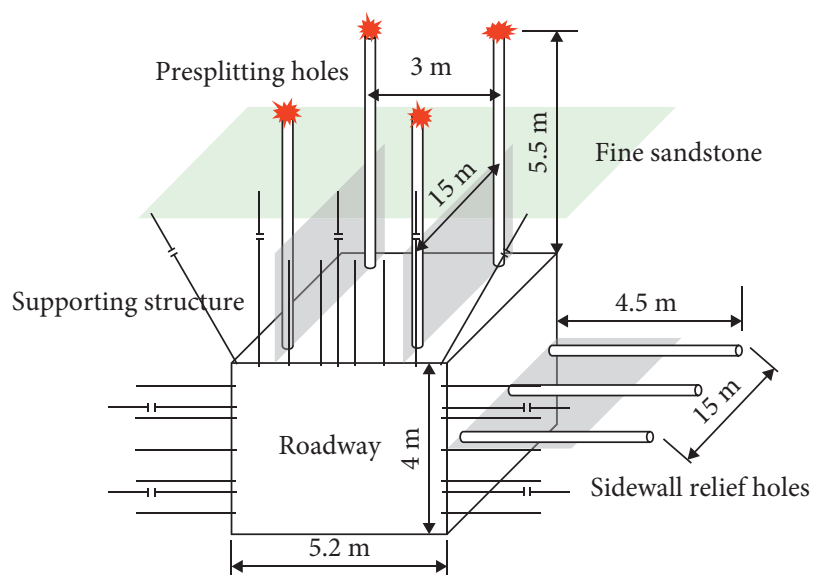

FIGURE 14: Layout scheme of roof presplitting and sidewall pressure relief holes.

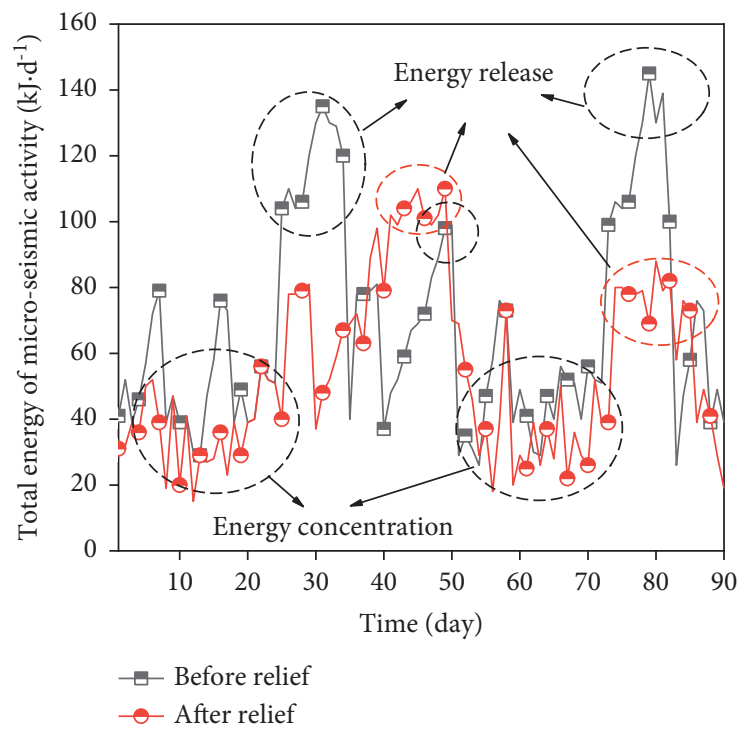

(a)

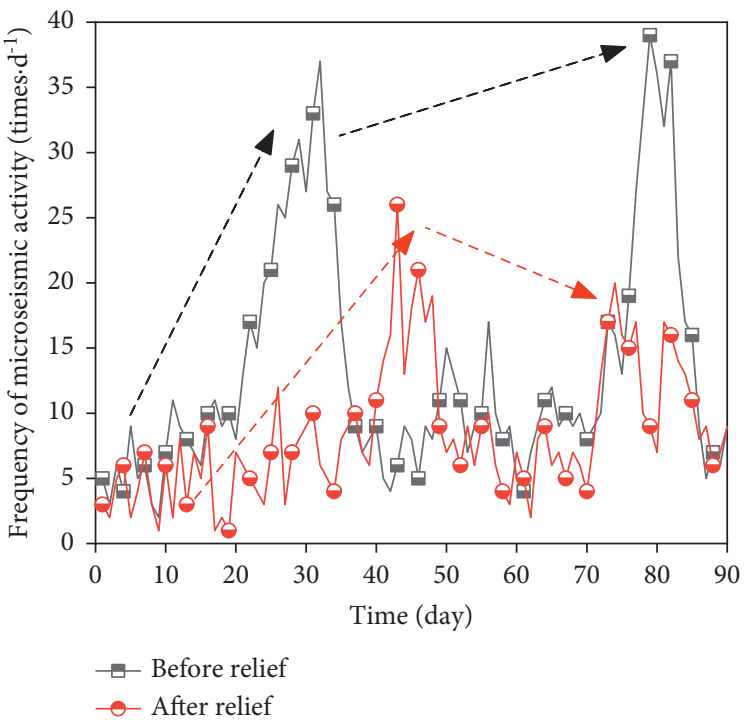

(b)

FIgURE 15: Microseismic activity during roadway excavation. (a) Total energy. (b) Frequency.

Figure 15 gives the variation of total energy and frequency distribution of microseismic activity during roadway excavation before and after relief. After adopting the control methods of sidewall borehole relief and roof presplitting, the intensity and frequency of microseismic activity decreased significantly. Due to the weakening of the microseismic activity and the decrease of microseismic frequency, the release time of microseismic energy is prolonged, and the gathering time before the release of energy is also longer, which is not enough to produce instantaneous large impact damage to the surrounding rock of roadway.

\section{Conclusions}

The occurrence of roadway rock burst is the result of the interaction between the dynamic disturbance source and the surrounding rock supporting structure. The results of discrete element analysis show that the collapse and instability of the surrounding rock will occur in a large area under the cyclic dynamic load of the roof, and the anchoring effect of the ordinary supporting form of the surrounding rock cannot be fully played, resulting in the destruction of surrounding rock and the failure of supporting structure. Under the impact load of the roof, the total stress acting on the surrounding rock increases instantly, and the ratio of the total stress of roadway surrounding rock to the strength of anchor solid support determines the damage degree of the rock burst.

The essence of rock burst is the process of energy accumulation and instantaneous release. Before the occurrence of rock burst, there are often abnormal energy fluctuations, which can be used as the basis for microseismic monitoring and acoustic emission monitoring. Therefore, the monitoring and early warning of a large area mine and a mining area and the anti-impact and strengthening support of the surrounding rock in a small area are the key links of roadway rock burst prevention and control. 
In addition, on the basis of the comprehensive analysis of mechanism of the seismic disturbed rock burst, the method of combining roof presplitting with sidewall drilling relief holes is put forward. The field microseismic monitoring data show that the roadway impact risk is relieved in the process of roadway excavation, which can provide a reference for the impact prevention and control of the similar deep buried roadway.

\section{Data Availability}

The data used to support the findings of this study are available from the corresponding author upon request.

\section{Conflicts of Interest}

The authors declare no conflicts of interest.

\section{Acknowledgments}

The authors acknowledge the financial support for this work by the project supported by the Scientific and Technological Research Program of Chongqing Municipal Education Commission (grant no. KJQN201900727).

\section{References}

[1] T. B. Zhao, W. Y. Guo, Y. L. Tan, C. P. Lu, and C. W. Wang, "Case histories of rock bursts under complicated geological conditions," Bulletin of Engineering Geology and the Environment, vol. 77, no. 04, pp. 1529-1545, 2018.

[2] S. You, H. G. Ji, Z. J. Zhang, and C. H. Zhang, "Damage evaluation for rock burst proneness of deep hard rock under triaxial cyclic loading," Advances in Civil Engineering, vol. 2018, Article ID 8193638, 8 pages, 2018.

[3] T. W. Lan, J. W. Sun, A. S. Batugin et al., "Dynamic characteristics of fault structure and its controlling impact on rock burst in mines," Shock and Vibration, vol. 2021, Article ID 7954876, 7 pages, 2021.

[4] Z. H. Wu, P. Z. Pan, P. Konicek, S. K. Zhao, J. Q. Chen, and X. D. Liu, "Spatial and temporal microseismic evolution before rock burst in steeply dipping thick coal seams under alternating mining of adjacent coal seams," A rabian Journal of Geosciences, vol. 14, no. 20, p. 28, Article ID 2097, 2021.

[5] Z. Wang, L. Gu, Q. Zhang, and B.-A. Jang, "Influence of initial stress and deformation states on the shear creep behavior of rock discontinuities with different joint roughness coefficients," Rock Mechanics and Rock Engineering, vol. 54, no. 11, pp. 5923-5936, 2021, https://doi.org/10.1007/s00603-02102633-6.

[6] S. T. Ji, J. Zhang, R. K. Pan, and J. Karlovsek, "Local acceleration monitoring and its application in physical modelling of underground mining," International Journal of Rock Mechanics and Mining Sciences, vol. 128, p. 12, Article ID 104282, 2020.

[7] X. Wang and F. B. Meng, "Statistical analysis of large accidents in China's coal mines in 2016," Natural Hazards, vol. 92, no. 1, pp. 311-325, 2018.

[8] W. Shen, L. M. Dou, H. He, and G. A. Zhu, "Rock burst assessment in multi-seam mining: a case study," Arabian Journal of Geosciences, vol. 10, no. 8, p. 11, 2017.

[9] S. T. Ji, H. He, and J. Karlovsek, "Application of superposition method to study the mechanical behaviour of overlying strata in longwall mining," International Journal of Rock Mechanics and Mining Sciences, vol. 146, no. 4, p. 15, Article ID 104874, 2021.

[10] T. B. Zhao, W. Y. Guo, Y. L. Tan, Y. C. Yin, L. S. Cai, and J. F. Pan, "Case studies of rock bursts under complicated geological conditions during multi-seam mining at a depth of 800 m," Rock Mechanics and Rock Engineering, vol. 51, no. 05, pp. 1539-1564, 2018.

[11] K. Y. Zhou, L. M. Dou, S. Y. Gong, J. Z. Li, J. K. Zhang, and J. R. Cao, "Study of rock burst risk evolution in front of deep longwall panel based on passive seismic velocity tomography," Geofluids, vol. 2020, Article ID 8888413, 14 pages, 2020.

[12] T. W. Lan, C. J. Fan, J. Han, H. W. Zhang, and J. W. Sun, "Controlling mechanism of rock burst by co2 fracturing blasting based on rock burst system," Shock and Vibration, vol. 2020, Article ID 8876905, 9 pages, 2020.

[13] Z. M. Xiao, J. Liu, S. T. Gu et al., "A control method of rock burst for dynamic roadway floor in deep mining mine," Shock and Vibration, vol. 2019, Article ID 7938491, 17 pages, 2019.

[14] A. Y. Cao, L. M. Dou, C. B. Wang, X. X. Yao, J. Y. Dong, and $\mathrm{Y}$. Gu, "Microseismic precursory characteristics of rock burst hazard in mining areas near a large residual coal pillar: a case study from Xuzhuang Coal Mine, Xuzhou, China," Rock Mechanics and Rock Engineering, vol. 49, no. 11, pp. 4407-4422, 2018.

[15] J. C. Wang, F. X. Jiang, X. J. Meng, X. Y. Wang, S. T. Zhu, and Y. Feng, "Mechanism of rock burst occurrence in specially thick coal seam with rock parting," Rock Mechanics and Rock Engineering, vol. 49, no. 5, pp. 1953-1965, 2016.

[16] W. Cai, L. Dou, M. Zhang, W. Cao, J.-Q. Shi, and L. Feng, "A fuzzy comprehensive evaluation methodology for rock burst forecasting using microseismic monitoring," Tunnelling and Underground Space Technology, vol. 80, pp. 232-245, 2018.

[17] G. Q. Chen, T. B. Li, G. F. Zhang, H. Y. Yin, and H. Zhang, "Temperature effect of rock burst for hard rock in deep-buried tunnel," Natural Hazards, vol. 72, no. 2, pp. 915-926, 2014.

[18] W. L. Zhang, N. J. Ma, J. Ma, C. Li, and J. J. Ren, "Mechanism of rock burst revealed by numerical simulation and energy calculation," Shock and Vibration, vol. 2020, Article ID 8862849, 15 pages, 2020.

[19] S. Q. He, D. Z. Song, X. Q. He et al., "Coupled mechanism of compression and prying-induced rock burst in steeply inclined coal seams and principles for its prevention," Tunnelling and Underground Space Technology, vol. 98, p. 22, Article ID 103327, 2020.

[20] J. R. Cao, L. M. Dou, G. A. Zhu, J. He, S. C. Wang, and K. Y. Zhou, "Mechanisms of rock burst in horizontal section mining of a steeply inclined extra-thick coal seam and prevention technology," Energies, vol. 13, no. 22, p. 20, Article ID 6043, 2020.

[21] D. M. Guo, X. C. Kang, Z. Y. Lu, and Q. Y. Chen, "Mechanism and control of roadway floor rock burst induced by high horizontal stress," Shock and Vibration, vol. 2021, Article ID 6745930, 13 pages, 2021.

[22] S. C. Hu, Y. L. Tan, J. G. Ning, W. Y. Guo, and X. S. Liu, "Multiparameter monitoring and prevention of fault-slip rock burst," Shock and Vibration, vol. 2017, Article ID 7580109, 9 pages, 2017.

[23] Z. H. Jiao, Q. P. Yuan, P. Zou, and B. J. Shi, "Case study of the characteristics and mechanism of rock burst near fault in Yima Coalfield, China," Shock and Vibration, vol. 2021, Article ID 9950273, 12 pages, 2021.

[24] W. J. Guo, Y. Y. Li, D. W. Yin, S. C. Zhang, and X. Z. Sun, "Mechanisms of rock burst in hard and thick upper strata and 
rock-burst controlling technology," Arabian Journal of Geosciences, vol. 9, no. 10, p. 11, 2016.

[25] L. L. Gu, Z. Wang, Q. Huang, G. L. Ye, and F. Zhang, "Numerical investigation into ground treatment to mitigate the permanent train-induced deformation of pile-raft-soft soil system," Transportation Geotechnics, vol. 24, p. 11, Article ID 100368, 2020.

[26] P. F. Lyu, X. H. Chen, G. B. Chen, and L. Qiu, "Experimental study on dynamic mechanical responses of coal specimens under the combined dynamic-static loading," Arabian Journal of Geosciences, vol. 13, no. 18, p. 11, 2020. 